\title{
The role of mindfulness and self-compassion in depressive symptoms and affect: A Comparison between Cancer Patients and Healthy Controls
}

\author{
Loek J. van der Donk ${ }^{1}$ (D) Joke Fleer ${ }^{1} \cdot$ Annika Tovote $^{1} \cdot$ Adelita V. Ranchor $^{1} \cdot$ Ans Smink $^{1} \cdot$ Veronique E. M. Mul $^{2}$. \\ Robbert Sanderman ${ }^{1,3} \cdot$ Maya J. Schroevers ${ }^{1}$
}

Published online: 29 January 2020

(C) The Author(s) 2020

\begin{abstract}
Objectives Mindfulness and self-compassion are related to psychological well-being and can be regarded as personal resources. It is, however, unclear whether these resources are always beneficial (direct effect) or only in stressful circumstances (buffer effect). We therefore examined whether mindfulness and self-compassion are equally or more strongly related to depressive symptoms and affect in cancer patients, compared to healthy controls.

Methods Using a case-control design, 245 cancer patients were matched to 245 healthy controls (without chronic somatic comorbidities). Both groups filled out questionnaires concerning mindfulness (Five Facet Mindfulness Questionnaire), selfcompassion (Self-Compassion Scale), depressive symptoms (Center for Epidemiologic Studies Depression Scale), and affect (Positive and Negative Affect Scale). Using correlation and regression analyses, we examined within both groups the associations for mindfulness (i.e., total score and five facets) and self-compassion (i.e., total score, two factors and six facets) with depressive symptoms and affect.

Results Mindfulness and self-compassion were equally strongly related to depressive symptoms and affect in cancer patients versus healthy controls. Mindfulness facets Act with awareness and Non-judgment were strongly related to depressive symptoms, negative affect, and the negative self-compassion factor. In contrast, mindfulness facets Describe and Observe were strongly related to positive affect and the positive self-compassion factor. When distinguishing the six self-compassion facets, Isolation and Mindfulness were strongly related to depressive symptoms, Over-identification to negative affect, and Mindfulness to positive affect.

Conclusions Results suggest that mindfulness and self-compassion are basic human personal resources associated with psychological functioning, regardless of the presence or absence of stressful life experiences.
\end{abstract}

Keywords Stress $\cdot$ Buffer $\cdot$ Depressive symptoms $\cdot$ Affect $\cdot$ Case-control

According to stress-coping models (Lazarus and Folkman 1984; Moos and Schaefer 1993), people have personal resources (e.g.,

Loek J. van der Donk

1.j.van.der.donk@umcg.nl

1 University Medical Center Groningen, Department of Health Psychology, University of Groningen, 9700 RB Groningen, Netherlands

2 University Medical Center Groningen, Department of Radiation Oncology, University of Groningen, 9700 RB Groningen, Netherlands

3 Department of Psychology, Health and Technology, University of Twente, 7522 NB Enschede, Netherlands internal traits or dispositions) and social resources (e.g., external support, time, money) that determine their psychological functioning and adaptation to stress. Some resources may always be beneficial and directly related to psychological functioning (regardless of the presence of stress), whereas others may be particularly important in stressful circumstances (so-called buffer effect). Mindfulness and self-compassion have been related to psychological well-being and can be regarded as personal resources (Keng et al. 2011; Macbeth and Gumley 2012; Sirois and Rowse 2016). As personal resources, they have the ability to influence (i.e., moderate) the way in which stressors are perceived and coped with. So far, it is not clear whether these resources are always beneficial for psychological functioning or particularly in stressful circumstances. 
Having had cancer has been shown to be greatly stressful to patients (Pinto-Gouveia et al. 2014; Schellekens et al. 2017), and this context provides a way to test the potential direct or buffer effects of mindfulness and self-compassion. That is, previous research in cancer patients has shown that some resources (e.g., self-esteem, perceived emotional support) had a direct effect on psychological functioning, whereas other resources (e.g., a lack of actual emotional supportive interactions) were more strongly related to depressive symptoms in cancer patients, suggesting a buffering effect (Schroevers et al. 2003). Also studies comparing people with a chronically illness with healthy controls found that some resources had a direct effect and some a buffer effect (e.g., mastery) (Bisschop et al. 2004; Penninx et al. 1998). Little is known about the possible beneficial direct and buffer effects of mindfulness and self-compassion.

Mindfulness has been defined as a state of being attentive to and aware of what is taking place in the present, with an open, accepting and non-judgmental attitude (Brown and Ryan 2003). It can be regarded as a multidimensional concept, including facets related to attention regulation, nonelaborative awareness, as well as holding an attitude of nonjudgment (Baer et al. 2008; Bishop et al. 2004). It has been hypothesized that mindfulness may help people to cope with stressful situations (i.e., buffer effect) (Bishop et al. 2004). However, it can also been hypothesized that being more open and fully aware in the present moment is in general important for psychological functioning (i.e., direct effect).

Previous research has shown a positive association in healthy individuals between mindfulness and psychological outcomes (such as depressive symptoms, negative affect, positive affect) (Bränström et al. 2011; Cash and Whittingham 2010; Nyklíček and Kuijpers 2008; Snippe et al. 2015). Studies in people with cancer found somewhat stronger associations of mindfulness with lower depressive symptoms (Chambers et al. 2016; Schellekens et al. 2017), whereas others found associations of comparable strength as in the general population (Garland et al. 2013a). Studies that have explicitly examined a buffering effect of mindfulness generally found weak support for this, as indicated by small and inconsistent interactions between stress (e.g., in terms of perceived stress, presence of life hassles) and mindfulness (Bergin and Pakenham 2016; Bränström et al. 2011; Brown et al. 2012; Ciesla et al. 2012; Garland et al. 2013a; Marks et al. 2010). Overall, these findings suggest that mindfulness is beneficial in a wide range of circumstances and populations (differing in demographics and health status), but given the conflicting findings and great differences between the studied populations, it is difficult to draw conclusions about the role of mindfulness for well-being in healthy versus chronically ill individuals.
Self-compassion can be described as compassion directed inward, relating to ourselves as the object of care and concern when faced with the experience of suffering (Neff 2003). Given the definition of self-compassion, with a focus on being of importance when facing suffering, it can be hypothesized that self-compassion is particularly important when facing stressful life circumstances. Three meta-analyses (mainly including studies among students) found a strong inverse association of self-compassion with depressive symptoms (Macbeth and Gumley 2012; Muris and Petrocchi 2017; Zessin et al. 2015). Among cancer patients, similar relationships between self-compassion and psychological functioning have been found (Schellekens et al. 2017), also in the context of a self-compassion training (Campo et al. 2017), although one study found stronger associations of self-compassion with psychological functioning in cancer patients compared to those found in the general population (Pinto-Gouveia et al. 2014). As with research on mindfulness, it should be noted that there was also considerable variety in the strength of the associations of self-compassion with psychological functioning among the different samples. No studies were found that included a measure of stress and tested a potential buffering effect of self-compassion. So far, only one study compared cancer patients with healthy individuals (Pinto-Gouveia et al. 2014), but given the small sample size and differences in demographic characteristics of the two samples, it is difficult to draw conclusions about direct and buffer effects of selfcompassion.

So far, no studies have investigated differences between cancer patients and healthy people in the relationships between mindfulness, self-compassion, and psychological functioning. Insight into these potential differences may indicate whether mindfulness and self-compassion based interventions need to be adapted to the context of cancer. In addition, it is important to distinguish positive and negative indicators of psychological functioning, as previous research found that associations of mindfulness and self-compassion with psychological functioning differ when distinguishing positive and negative psychological outcomes (López et al. 2016). Second, given the current debate about the number of facets of self-compassion (Coroiu et al. 2018; Kumlander et al. 2018; Muris et al. 2018; Neff et al. 2018a, b, 2017), selfcompassion total scores as well as distinct facets need to be taken into account. That is, with respect to self-compassion, several studies have recently suggested a two factor model (instead of the original six facets), distinguishing a positive self-compassion factor (i.e., a combination of self-kindness, common humanity, mindfulness) and a negative selfcompassion factor (i.e., a combination of Self-judgment, Isolation, Mindfulness, Over-identification) (Costa et al. 2016; López et al. 2015; Petrocchi et al. 2014). Identifying which facets of mindfulness and self-compassion are most strongly related to positive and negative psychological 
outcomes is a first step in clarifying possible mechanisms of change explaining how these interventions work. Such knowledge may be used to optimize future mindfulness and compassion-based interventions (Neff 2016), although it should be taken into account that mindfulness and/or selfcompassion-based interventions may affect a range of mindfulness and self-compassion facets simultaneously.

So far, several studies have shown that certain facets of mindfulness and self-compassion are more strongly associated with health outcomes than others (Bränström et al. 2011; Cash and Whittingham 2010; Christopher et al. 2012; Garland et al. 2013a; Körner et al. 2015; Pinto-Gouveia et al. 2014; Sirois and Rowse 2016). Evidence from intervention research is mixed regarding which facets are cultivated and most strongly related to improved outcomes (Bränström et al. 2010; Takahashi et al. 2019; Witek-Janusek et al. 2019). Distinguishing the positive and negative facets of mindfulness and self-compassion may show whether improved outcomes are better explained by decreasing negative behaviors (e.g., self-criticism, functioning on automatic pilot) and/or increasing positive behaviors (e.g., acceptance, self-kindness, observing internal/external stimuli) and whether this depends on the type of population and outcome that is targeted by the intervention (e.g., increasing positive affect or reducing depression) (Muris and Petrocchi 2017).

The present study aimed to examine whether mindfulness and self-compassion are equally or more strongly related to depressive symptoms and negative affect and positive affect under stressful circumstances (i.e., having received a cancer diagnosis), compared to healthy controls (i.e., without any chronic somatic condition). Based on the lack of previous studies and conflicting findings of those that did study such direct and buffer effects of mindfulness and self-compassion, no specific hypotheses were formulated.

\section{Method}

\section{Participants}

In this case-control study, a group of cancer patients was compared with a group of matched healthy controls, without a chronic somatic condition. Cancer patients met inclusion criteria if they were treated with curative intent, received a cancer diagnosis maximally 5 years ago and finished radiotherapy treatment for at least 2 months. Exclusion criteria were age younger than 18, having breast cancer (excluded due to ongoing studies at the time), not being able to read Dutch, and a serious psychiatric disorder. For healthy controls, exclusion criteria were age younger than 18 and not being able to read Dutch. Among healthy controls, there were cases reporting (a history of) presence of a malignity (171) or other somatic comorbidities (707) and these were therefore later excluded.
Mean age in both groups was 64.7 years, with $71.8 \%$ being male. The total group was evenly distributed regarding education, categorized into low $(28.8 \%)$, middle $(39.0 \%)$, and highly educated individuals $(32.2 \%)$. Concerning the cancer patients, more than half of them $(55.3 \%)$ received the diagnosis longer than 2 years ago. Most common cancer type was urological cancer $(52.8 \%)$. Surgery with radiotherapy was the most frequently received therapy $(30.2 \%)$. In total 39 out of $243(16.0 \%)$ reported a recurrence of cancer.

\section{Procedure}

The institutional review board of the University Medical Center of Groningen (UMCG), the Netherlands, approved the study. Cancer patients were recruited through the department of radiation oncology of the UMCG from April 2011 until November 2011. In total, 762 eligible patients were approached by their radiation oncologist during a regular consult in which they were given information about the study and an informed consent with a return envelope. Those who consented received a questionnaire. In total, 252 cancer patients gave informed consent and returned the full questionnaires, of which 7 individuals were excluded. One patient ID was invalid, one individual did not fill in educational level which was required for successful matching, one patient did not receive a cancer diagnosis but was under radio treatment for a benign condition and four patients received a diagnosis more than 5 years earlier, resulting in a total sample of 245 cancer patients.

Healthy controls were selected from the register office of the township in the same region as the cancer patients. A community-based sample was selected, based on age and gender distribution representative of the Dutch population. In total 7,492 adults were approached for this study. Healthy controls received an information letter explaining the aim of the study and an informed consent. Those returning the informed consent, were invited to complete and send back a self-report questionnaire in a return envelope. The questionnaire used was similar to the one used for cancer patients as described above, apart from the cancer-related variables missing. In total, 1,736 individuals completed the full questionnaire. More information about the screening procedure can be found elsewhere (López et al. 2015). The final sample before matching involved 1,084 individuals in total, of which 839 were healthy controls and 245 cancer patients.

Cancer patients were matched to healthy controls on variables age, gender and educational level by using Propensity Score Matching. If participants had missing values on any of these variables, they were excluded because matching was not possible. For this procedure R Studio 1.0.44 was used (utilizing the MatchIt plugin), entering variables in the order "gender," "age," and "education" and using method Nearest Neighbor Matching with a ratio of 1:1. This resulted in 245 
cancer patients and 245 healthy controls. Successful matching (1:1) was obtained since age, gender, and education were not significantly different for cancer patients compared to controls. Data were then exported to SPSS for further analyses.

\section{Measures}

\section{Demographics and Clinical Variables}

Information concerning sociodemographic variables including age, gender, education, and chronic somatic comorbidities was gathered by means of self-report. Education level was divided into low, middle, and highly educated. In case of lacking or peculiar data on cancer-related variables, patients' medical records were used for checking authenticity.

\section{Depressive Symptoms}

Depressive symptoms were measured with the Center of Epidemiologic Studies (CES-D) scale (Bouma et al. 1995; Radloff 1977). This is a 20-item questionnaire, with each item ranging from 0 to 3 . Sum score ranges from 0 to 60 , with a higher score indicating more depressive symptoms. In general, a cutoff of $\geq 16$ is used for determining elevated depressive symptoms. Internal consistency in this study was good ( $\alpha=$ 0.84 for cancer patients and $\alpha=0.82$ for healthy controls).

\section{Positive and Negative Affect}

Positive and negative affect was measured by the 20 -item Positive and Negative Affect Scale (PANAS) (Peeters et al. 1999; Watson et al. 1988). This instrument involved two 10item scales assessing feelings of activeness, enthusiasm, and alertness (i.e., positive affect) versus subjective distress and unpleasant engagement (i.e., negative affect). Higher scores indicate more positive and negative affect. Participants were asked to indicate to what extent they perceived the particular emotion the previous week (i.e., 1 very slightly/not at all until 5 extremely). Cronbach's $\alpha$ was good with $0.89-0.90$ for positive affect and $0.88-0.88$ for negative affect.

\section{Mindfulness}

Mindfulness was assessed using the 39-item Five Facets of Mindfulness Questionnaire (FFMQ), consisting of five facets: Observe, Describe, Act with awareness, Non-judgment, and Non-reactivity (Baer et al. 2006; de Bruin et al. 2012). Each item involves a statement, which participants have to rate on a 5 -point Likert scale (1 indicates never/almost never and 5 very often/always). Scores for the five facets can be calculated by recoding negative items and subsequently summing the totality, with higher scores indicating higher levels of mindfulness. The facets Act with awareness and Non-judgment only consist of negatively formulated items, and all items of these facets therefore needed to be reversed. Cronbach's $\alpha$ for subscales in our study was acceptable: $0.76-0.75$ (Observe), 0.82-0.84 (Describe), 0.87-0.85 (Act with awareness), 0.84-0.83 (Non-judgment), and 0.81-0.77 (Non-reactivity).

\section{Self-Compassion}

Self-compassion was measured using the Self-Compassion Scale (SCS), with scores ranging from 24 to 120 (Neff 2003; Neff and Vonk 2009). The Dutch version of the SCS has been validated and contains 24 items instead of 26 items, due to difficulties in translation (Neff and Vonk 2009). Items are rated on a 5-point Likert scale (1 indicates seldom/never and 5 almost always), with higher scores indicating more selfcompassion. Given the conflicting results in the literature concerning the amount of self-compassion facets (Coroiu et al. 2018; Muris et al. 2018; Neff et al. 2018a, b, 2017), we executed exploratory factor analysis (EFA), confirmatory factor analysis (CFA), and exploratory structural equation modeling (ESEM) to detect the underlying structure for the Dutch version of the SCS (Neff and Vonk 2009). EFA suggested a two-factor model, whereas CFA results showed a non-sufficient fit of all models (i.e., one-factor, two-factor, six-factor, bifactor, two-bifactor). ESEM showed sufficient fit for a six-factor and bifactor (one general factor, six subfactors) model (in line with findings from the original author (Neff et al. 2018b)), but these two models had poor factor loadings for facets Mindfulness (bifactor model) and Overidentification (both models). Given these results and those of previous research regarding the SCS factor structure, the current study presents results using a total SCS score, two factors and six facets. Internal consistency was acceptable and good for the total SCS score $(\alpha=0.79-0.80)$, excellent for the two self-compassion factors, the positive factor $(\alpha=0.87-0.86)$ and negative factor $(\alpha=0.86-0.88)$; and mostly acceptable for the six facets Self-kindness $(\alpha=0.73-0.69)$, Selfjudgment ( $\alpha=0.71-0.72$ ), Common humanity $(\alpha=0.64$ $0.75)$, Isolation $(\alpha=0.76-0.82)$, Mindfulness $(\alpha=0.78$ $0.74)$, and Over-identification $(\alpha=0.70-0.76)$.

\section{Data Analyses}

Further statistical analyses were executed using SPSS 23.0. A group variable was created for cancer patients and controls. First, baseline characteristics were compared between the groups (including the three matched variables to guarantee successful matching) using ANOVAs for continuous variables and chi-square tests for categorical variables to detect statistically significant differences. Cancer-related variables (e.g., time since diagnosis, cancer type) were also included for the cancer patients. Then descriptive characteristics for both groups were calculated for depressive symptoms, affect, 
mindfulness (with subscales Observe, Describe, Act with awareness, Non-judgment, Non-reactivity), and selfcompassion (with the two factors: the positive factor and negative factor as well as the six facets Self-kindness, Self-judgment, Common humanity, Isolation, Mindfulness, and Overidentification).

Subsequently, a correlation matrix was performed to reveal associations between mindfulness and self-compassion with depressive symptoms and positive and negative affect. Then, in total 15 regression analyses were performed: 3 analyses for mindfulness total scores and outcomes (i.e., depressive symptoms, positive affect, and negative affect as outcome respectively), 3 analyses distinguishing the five mindfulness facets, 3 analyses for self-compassion total scores, 3 analyses using the 2 self-compassion factors, and 3 analyses including the 6 self-compassion facets. To check for multicollinearity, bivariate correlations between all predictors and VIF values were examined. Neither the correlations (all below $<0.80$ ) or the VIF (all values below 2) indicated multicollinearity. In order to detect whether the analyses were sufficiently powered for detecting a significant effect, we linked the sample size to the amount of predictors in the analyses. A conservative criterion is that at least 10 to 15 subjects per predictor are required for detecting an effect (Harrell 2001). Our study complied to this rule, since our regression analysis with the most predictors had 13 predictors and our sample size was 490 (i.e. 245 cancer patients and 245 healthy controls).

\section{Results}

Sample characteristics are shown in Table 1. We found significant differences between cancer patients and matched controls in levels of depressive symptoms $(p=0.014)$ and negative affect $(p=0.018)$ but not for levels of positive affect ( $p=$ 0.106). Regarding mindfulness, total scores did not significantly differ but facets Act with awareness $(p<0.001)$ and Non-judgment $(p<0.001)$ were higher in cancer patients, whereas Observe $(p<0.001)$ was higher in healthy controls (Table 2). For self-compassion, total scores did not significantly differ between the groups and neither did the two self-compassion factors, although cancer patients tended to score lower on the negative factor compared to matched controls $(p=0.053)$. Regarding the six facets of self-compassion, only Isolation was higher for controls compared to cancer patients $(p=0.007)$ (Table 2).

With respect to mindfulness, total scores were significantly related to depressive symptoms, negative and positive affect. Facets Describe, Act with awareness and Non-judgment were significantly associated with depressive symptoms in both cancer patients and healthy controls (Table 3), but facet Non-reactivity only in healthy controls. Partly similar results were found for Act with awareness and Non-judgment with negative affect, with Describe and Observe only significant in cancer patients and Non-reactivity not significant in either group. All facets of mindfulness, except for Non-judgment were significantly associated with positive affect in both groups. With respect to self-compassion, the total score was related to depressive symptoms, negative and positive affect. Regarding the two self-compassion factors, the negative factor was related to depressive symptoms and negative affect in both groups, whereas the positive factor was related to positive affect. The positive factor was somewhat stronger correlated to positive affect in cancer patients than in matched controls. For the six facets of self-compassion, Self-judgment, Isolation, Mindfulness, and Over-identification were significantly associated with depressive symptoms for both groups and similar results were found for negative affect. Selfkindness and Mindfulness were strongest associated with positive affect in both groups and Common Humanity and Isolation only in controls.

Regression analyses revealed that after adjustment for "Group," "Total Mindfulness" inversely predicted depressive symptoms and negative affect, but no interactions effects (i.e., total mindfulness*group) were found (Table 4). Regarding the five mindfulness facets, Non-judgment and Act with awareness significantly and mostly (inversely) predicted depressive symptoms and negative affect. Overall, we found no significant interaction effects between mindfulness facets and group (i.e., cancer patients versus healthy controls) except for a significant but weak interaction effect of Non-judgment on depressive symptoms. Observe and Describe mainly predicted positive affect. No significant interactions between mindfulness facets and group were found for positive affect.

After adjustment for "Group," total self-compassion significantly predicted depressive symptoms, negative and positive affect (Table 5). A weak interaction effect was found for total self-compassion with group on positive affect, but not for depressive symptoms and negative affect. Concerning the two self-compassion factors, the negative factor mainly predicted depressive symptoms and negative affect, whereas the positive factor mainly predicted positive affect. No significant interaction effects of the two selfcompassion factors and group were found, suggesting no significant differences between cancer patients and healthy controls in the association of the two self-compassion factors with depressive symptoms, negative and positive affect. Regarding the six self-compassion facets, Isolation positively and Mindfulness negatively were strongest predictors of depressive symptoms, whereas mainly Overidentification predicted negative affect. Positive affect was mainly predicted by Mindfulness. Similar to findings from the two factors, no significant differences between cancer patients and healthy controls were found in the association of the six self-compassion facets with depressive symptoms, and negative and positive affect. 
Table 1 Demographic and medical characteristics of cancer patients with healthy controls matched on age, gender, and education

\begin{tabular}{|c|c|c|c|c|c|}
\hline & \multicolumn{2}{|c|}{ Cancer patients } & \multicolumn{2}{|c|}{ Matched controls } & $p$ value \\
\hline \multicolumn{6}{|l|}{ Demographic variables } \\
\hline $\mathrm{N}(\%)$ & 245 & 50 & 245 & 50 & \\
\hline Age (mean, sd) & 65.35 & 12.01 & 64.11 & 12.11 & 0.257 \\
\hline \multicolumn{6}{|l|}{ Gender (N, \%) } \\
\hline Male & 184 & 75.1 & 168 & 68.6 & 0.132 \\
\hline \multicolumn{6}{|l|}{ Education (N, \%) } \\
\hline Low & 77 & 31.4 & 64 & 26.1 & 0.353 \\
\hline Middle & 89 & 36.3 & 102 & 41.6 & \\
\hline High & 79 & 32.2 & 79 & 32.2 & \\
\hline \multicolumn{6}{|l|}{ Cancer-related variables } \\
\hline Years since diagnosis (mean, SD) & 2.39 & 1.39 & & & \\
\hline \multicolumn{6}{|l|}{ Years since diagnosis $(\mathrm{N}, \%)$} \\
\hline$\leq 2$ year & 110 & 44.9 & & & \\
\hline$>2$ year & 135 & 55.1 & & & \\
\hline \multicolumn{6}{|l|}{ Cancer type (N, \%) } \\
\hline Urological & 124 & 52.8 & & & \\
\hline Lung & 20 & 8.5 & & & \\
\hline Colorectal & 15 & 6.4 & & & \\
\hline Hematological & 16 & 6.8 & & & \\
\hline Gynecological & 20 & 8.5 & & & \\
\hline Bone \& soft tissue & 7 & 3.0 & & & \\
\hline Other & 5 & 2.1 & & & \\
\hline Mixed & 28 & 11.9 & & & \\
\hline \multicolumn{6}{|l|}{ Received treatment $(\mathrm{N}, \%)$} \\
\hline RT & 58 & 25.0 & & & \\
\hline RT + surgery & 70 & 30.2 & & & \\
\hline $\mathrm{RT}+$ chemo & 34 & 14.7 & & & \\
\hline RT + surgery + chemo & 26 & 11.2 & & & \\
\hline $\mathrm{RT}+$ hormone & 19 & 8.2 & & & \\
\hline $\mathrm{RT}+$ surgery + hormone & 15 & 6.5 & & & \\
\hline Other & 10 & 4.3 & & & \\
\hline \multicolumn{6}{|l|}{ Recurrence (N, \%) } \\
\hline No & 204 & 84.0 & & & \\
\hline Yes & 39 & 16.0 & & & \\
\hline
\end{tabular}

*RT $=$ Radiotherapy Treatment

\section{Discussion}

Our study examined whether mindfulness and selfcompassion are differently associated with depressive symptoms and affect for individuals with cancer compared to healthy controls, in order to test whether these resources are always related to psychological well-being (i.e., a direct effect) or in particular when being in stressful circumstances, such as having had cancer (i.e., a buffer effect). Results showed that the strength of the associations of mindfulness and self-compassion with psychological functioning is about equally strong in cancer patients and healthy controls, suggesting that these resources are beneficial for psychological functioning irrespective of the presence of stressful circumstances (in our case a diagnosis of cancer). In both groups, we found that mindfulness and self-compassion were inversely associated with depressive symptoms and negative affect, in particular the mindfulness facets Non-judgment and Act with awareness and for self-compassion the negative factor and facets Isolation, Mindfulness and Over-identification. Strongest associations with positive affect were found for the mindfulness facets Observe and Describe and the positive self-compassion factor and the facet Mindfulness.

Our findings suggest that mindfulness and self-compassion are basic resources and that having these resources available is always beneficial for psychological functioning, not only in the 
Table 2 Descriptive characteristics (mean and standard deviation) of cancer patients and healthy controls matched on age, gender and education on depressive symptoms, affect, mindfulness, and self-compassion (including facets)

Table 3 Inter-correlations between predictors mindfulness and self-compassion facets and outcomes depressive symptoms, negative and positive affect

\begin{tabular}{|c|c|c|c|c|c|c|c|}
\hline & \multicolumn{2}{|l|}{$\begin{array}{l}\text { Cancer } \\
\text { patients }\end{array}$} & \multicolumn{2}{|c|}{$\begin{array}{l}\text { Matched } \\
\text { controls }\end{array}$} & \multicolumn{2}{|l|}{ Total } & \multirow[t]{2}{*}{$p$ value } \\
\hline & M & SD & M & $\mathrm{SD}$ & M & SD & \\
\hline Depressive symptoms & 9.57 & 7.79 & 7.96 & 6.53 & 8.76 & 7.22 & 0.014 \\
\hline Negative affect & 15.44 & 5.71 & 14.27 & 5.20 & 14.86 & 5.49 & 0.018 \\
\hline Positive affect & 29.79 & 7.43 & 28.65 & 8.03 & 29.22 & 7.75 & 0.106 \\
\hline Mindfulness (total) & 133.85 & 15.85 & 131.86 & 14.54 & 132.85 & 15.22 & 0.150 \\
\hline Observe & 22.83 & 6.39 & 24.64 & 5.35 & 23.74 & 5.96 & $<0.001$ \\
\hline Describe & 27.65 & 5.93 & 27.32 & 5.39 & 27.49 & 5.66 & 0.520 \\
\hline Act with awareness & 31.98 & 6.70 & 29.48 & 5.60 & 30.73 & 6.29 & $<0.001$ \\
\hline Non-judgment & 31.84 & 6.62 & 29.47 & 6.06 & 30.66 & 6.45 & $<0.001$ \\
\hline Non-reactivity & 20.46 & 5.72 & 21.21 & 4.81 & 20.84 & 5.28 & 0.122 \\
\hline Self-compassion (total) & 82.56 & 11.18 & 81.65 & 10.95 & 82.10 & 11.06 & 0.366 \\
\hline \multicolumn{8}{|l|}{ Two factors } \\
\hline Positive factor & 35.77 & 8.99 & 36.41 & 8.06 & 36.09 & 8.53 & 0.412 \\
\hline Negative factor & 25.42 & 8.08 & 26.90 & 8.58 & 26.17 & 8.36 & 0.053 \\
\hline \multicolumn{8}{|l|}{ Six facets } \\
\hline Self-kindness & 11.67 & 3.40 & 11.90 & 2.91 & 11.78 & 3.16 & 0.429 \\
\hline Self-judgment & 10.07 & 3.36 & 10.19 & 3.39 & 10.13 & 3.37 & 0.702 \\
\hline Common humanity & 11.38 & 3.49 & 11.80 & 3.42 & 11.59 & 3.46 & 0.187 \\
\hline Isolation & 7.51 & 3.16 & 8.32 & 3.39 & 7.92 & 3.30 & 0.007 \\
\hline Mindfulness & 12.67 & 3.55 & 12.71 & 3.08 & 12.69 & 3.32 & 0.881 \\
\hline Over-identification & 7.84 & 3.05 & 8.37 & 3.20 & 8.11 & 3.14 & 0.067 \\
\hline
\end{tabular}

\begin{tabular}{|c|c|c|c|c|c|c|}
\hline & \multicolumn{2}{|c|}{ Depressive symptoms } & \multicolumn{2}{|c|}{ Negative affect } & \multicolumn{2}{|c|}{ Positive affect } \\
\hline & $\begin{array}{l}\text { Cancer } \\
\text { patients }\end{array}$ & $\begin{array}{l}\text { Matched } \\
\text { controls }\end{array}$ & $\begin{array}{l}\text { Cancer } \\
\text { patients }\end{array}$ & $\begin{array}{l}\text { Matched } \\
\text { controls }\end{array}$ & $\begin{array}{l}\text { Cancer } \\
\text { patients }\end{array}$ & $\begin{array}{l}\text { Matched } \\
\text { controls }\end{array}$ \\
\hline Total mindfulness & $-0.471^{* *}$ & $-0.463^{* *}$ & $-0.399^{* *}$ & $-0.349^{* *}$ & $0.373^{* *}$ & $0.512^{* *}$ \\
\hline Observe & 0.023 & 0.042 & $0.209^{* *}$ & 0.120 & $0.304^{* *}$ & $0.298^{* *}$ \\
\hline Describe & $-0.308^{* *}$ & $-0.273^{* *}$ & $-0.298^{* *}$ & -0.123 & $0.406^{* *}$ & $0.310^{* *}$ \\
\hline Act with awareness & $-0.401^{* *}$ & $-0.463^{* *}$ & $-0.514^{* *}$ & $-0.449^{* *}$ & $0.197^{* *}$ & $0.153^{*}$ \\
\hline Non-judgment & $-0.414^{* *}$ & $-0.387^{* *}$ & $-0.461^{* *}$ & $-0.417^{* *}$ & 0.106 & 0.017 \\
\hline Non-reactivity & -0.057 & $-0.186^{* *}$ & 0.049 & -0.080 & $0.279^{* *}$ & $0.271^{* * *}$ \\
\hline Total self-compassion & $-0.474^{* *}$ & $-0.429^{* *}$ & $-0.369^{* *}$ & $-0.420^{* *}$ & $0.169^{* *}$ & $0.432^{* *}$ \\
\hline \multicolumn{7}{|l|}{ Two factors } \\
\hline Positive factor & $-0.158^{*}$ & $-0.160^{*}$ & -0.108 & 0.017 & $0.434^{* *}$ & $0.237^{* *}$ \\
\hline Negative factor & $0.416^{* *}$ & $0.450^{* *}$ & $0.472^{* *}$ & $0.489^{* * *}$ & -0.103 & 0.006 \\
\hline \multicolumn{7}{|l|}{ Six facets } \\
\hline Self-kindness & -0.120 & $-0.155^{*}$ & -0.090 & -0.022 & $0.217^{* *}$ & $0.387^{* *}$ \\
\hline Self-judgment & $0.290^{* * *}$ & $0.272^{* *}$ & $0.324^{* *}$ & $0.348^{* *}$ & 0.048 & -0.021 \\
\hline $\begin{array}{l}\text { Common } \\
\text { humanity }\end{array}$ & -0.044 & -0.023 & -0.032 & $0.131 *$ & 0.126 & $0.242^{* *}$ \\
\hline Isolation & $0.432^{* *}$ & $0.449^{* *}$ & $0.447^{* *}$ & $0.418^{* *}$ & -0.018 & $-0.176^{* *}$ \\
\hline Mindfulness & $-0.241^{* *}$ & $-0.247^{* *}$ & $-0.149^{*}$ & -0.081 & $0.274^{* *}$ & $0.482^{* *}$ \\
\hline Over-identification & $0.332^{* *}$ & $0.438^{* *}$ & $0.424^{* *}$ & $0.508^{* *}$ & 0.001 & -0.063 \\
\hline
\end{tabular}

*= correlation is significant at the 0.05 level

$* *=$ correlation is significant at the 0.01 level 
Table 4 (Facets of) mindfulness as predictors of depressive symptoms, negative affect and positive affect

\begin{tabular}{|c|c|c|c|c|c|c|c|c|c|}
\hline \multirow[b]{2}{*}{ Mindfulness (total score) } & \multicolumn{3}{|c|}{ Depressive symptoms } & \multicolumn{3}{|c|}{ Negative affect } & \multicolumn{3}{|c|}{ Positive affect } \\
\hline & $\beta$ & $\mathrm{t}$ & $\mathrm{R}^{2}$ & $\beta$ & $\mathrm{t}$ & $\mathrm{R}^{2}$ & $\beta$ & $\mathrm{t}$ & $\mathrm{R}^{2}$ \\
\hline \multicolumn{3}{|l|}{ Step 1} & 0.011 & & & 0.011 & & & 0.006 \\
\hline Group $^{\mathrm{a}}$ & $0.105^{*}$ & 2.323 & & $0.107 *$ & 2.351 & & 0.077 & 1.700 & \\
\hline \multicolumn{3}{|l|}{ Step 2} & 0.226 & & & & & & 0.198 \\
\hline Total Mindfulness & $-0.465^{* * *}$ & -11.548 & & $-0.375 * * *$ & -8.897 & 0.151 & $0.440 * * *$ & 10.722 & \\
\hline \multicolumn{3}{|l|}{ Step 3} & 0.227 & & & & & & 0.200 \\
\hline Total Mindfulness*group & -0.028 & -0.689 & & -0.027 & -0.645 & 0.152 & 0.035 & 0.852 & \\
\hline \multicolumn{10}{|l|}{ Mindfulness (five facets) } \\
\hline \multicolumn{3}{|l|}{ Step 1} & 0.012 & & & 0.011 & & & 0.006 \\
\hline Group $^{a}$ & $0.109 *$ & 2.393 & & $0.104 *$ & 2.292 & & 0.075 & 1.634 & \\
\hline \multicolumn{3}{|l|}{ Step 2} & 0.322 & & & 0.338 & & & 0.219 \\
\hline Observe & -0.060 & -1.324 & & 0.049 & 1.104 & & $0.262 * * *$ & 5.409 & \\
\hline Describe & $-0.096^{*}$ & -2.158 & & -0.035 & -0.801 & & $0.200 * * *$ & 4.213 & \\
\hline Act with awareness & $-0.292 * * *$ & -6.078 & & $-0.358 * * *$ & -7.490 & & $0.127 *$ & 2.466 & \\
\hline Non-judgment & $-0.321 * * *$ & -6.758 & & $-0.280 * * *$ & -5.936 & & 0.094 & 1.841 & \\
\hline Non-reactivity & $-0.124 * *$ & -2.856 & & -0.073 & -1.703 & & $0.123^{* *}$ & 2.636 & \\
\hline \multicolumn{3}{|l|}{ Step 3} & 0.332 & & & 0.342 & & & 0.224 \\
\hline Observe*group & -0.074 & -1.631 & & 0.003 & 0.066 & & -0.008 & -0.164 & \\
\hline Describe*group & 0.032 & 0.702 & & -0.036 & -0.793 & & -0.023 & -0.485 & \\
\hline Actaware*group & -0.002 & -0.037 & & -0.035 & -0.726 & & 0.023 & 0.447 & \\
\hline Nonjudge*group & $-0.105^{*}$ & -2.233 & & -0.019 & -0.409 & & 0.063 & 1.250 & \\
\hline Nonreact* group & 0.003 & 0.077 & & 0.006 & 0.139 & & 0.007 & 0.145 & \\
\hline \multicolumn{10}{|c|}{$*=$ is significant at the $p<0.05$ level } \\
\hline \multicolumn{10}{|c|}{$* *=$ is significant at the $p<0.01$ level } \\
\hline \multicolumn{10}{|c|}{$* * *=$ is significant at the $p<0.001$ level } \\
\hline $\mathrm{a}=$ Group was coded as $\mathrm{h}$ & trols & n & & & & & & & \\
\hline
\end{tabular}

presence of stressful life circumstances. Findings are in line with results of studies in distinct samples in the general population (Brown and Ryan 2003; Macbeth and Gumley 2012; Muris and Petrocchi 2017; Nyklíček and Kuijpers 2008; Snippe et al. 2015) and cancer patients (Brown and Ryan 2003; Chambers et al. 2016; Garland et al. 2013a; Pinto-Gouveia et al. 2014; Schellekens et al. 2017). When interpreting these results, it should be noted that there are different ways to examine the direct and buffer effects of resources. Based on previous literature that being diagnosed with cancer is associated with higher levels of depressive symptoms and negative affect (Mozaffarieh et al. 2007; Pinto-Gouveia et al. 2014; Schellekens et al. 2017), we assumed that having had cancer can be used as an indicator of stress. In line with this reasoning, we indeed found that cancer patients reported higher levels of depressive symptoms and negative affect compared to the healthy controls. We did not, however, include a direct measure of stress such as the report of amount of daily hassles (Ciesla et al. 2012; Marks et al. 2010) or perceived stress (Bränström et al. 2011). It can be argued that not only cancer patients but also controls were confronted with stress in their daily life, which we did not take into account in our analyses. Also, the time since cancer diagnosis varied greatly between cancer patients, making it possible that the impact of the diagnosis for some individuals was no longer greatly stressful.
Regarding the facets of mindfulness, especially Nonjudgment and Act with awareness were inversely associated with depressive symptoms and negative affect in our study. This is consistent with previous research showing that these facets are strongly related to psychological symptoms, both in healthy individuals (Baer et al. 2012; Barnhofer et al. 2011; Bränström et al. 2011; Cash and Whittingham 2010; Christopher et al. 2012) and in cancer patients (Garland et al. 2013a, b). One possibility for this finding is that items of these two mindfulness facets (i.e., Non-judgment and Act with awareness) are all comprised of negatively worded items, and previous research has shown that such negative facets tend to predict negative outcomes (e.g., depressive symptoms) (Neff et al. 2018a). The report of positive affect was in our study most strongly related to the mindfulness facets of Observe and Describe. Findings in the literature regarding these facets are mixed, with studies that found associations with positive outcomes (Bergin and Pakenham 2016), no associations with positive outcomes (Cash and Whittingham 2010) or only for facet Describe (Bränström et al. 2011; Christopher et al. 2012).

When distinguishing the two factors of self-compassion, depressive symptoms were significantly associated with higher levels of the negative factor of self-compassion, whereas positive affect was predominantly related to the positive 
Table 5 (Facets of) self-compassion as predictors of depressive symptoms, negative affect and positive affect

\begin{tabular}{|c|c|c|c|c|c|c|c|c|c|}
\hline \multirow[b]{2}{*}{ Self-compassion (total score) } & \multicolumn{3}{|c|}{ Depressive symptoms } & \multicolumn{3}{|c|}{ Negative affect } & \multicolumn{3}{|c|}{ Positive affect } \\
\hline & $\beta$ & $\mathrm{t}$ & $\mathrm{R}^{2}$ & $\beta$ & $\mathrm{t}$ & $\mathrm{R}^{2}$ & $\beta$ & $\mathrm{t}$ & $\mathrm{R}^{2}$ \\
\hline & 0.013 & & & 0.013 & & & 0.004 \\
\hline Group $^{\mathrm{a}}$ & $0.114^{*}$ & 2.506 & & $0.113^{*}$ & 2.494 & & 0.064 & 1.407 & \\
\hline \multicolumn{3}{|l|}{ Step 2} & 0.211 & & & 0.167 & & & 0.091 \\
\hline Total SCS & $-0.445^{* * *}$ & -10.930 & & $-0.393^{* * *}$ & -9.394 & & $0.295 * * *$ & 6.745 & \\
\hline \multicolumn{3}{|l|}{ Step 3} & 0.211 & & & 0.169 & & & 0.105 \\
\hline Total SCS*group & -0.014 & -0.355 & & -0.042 & -1.014 & & $0.119 * *$ & 2.744 & \\
\hline \multicolumn{10}{|l|}{ Self-compassion (two factors) } \\
\hline \multicolumn{3}{|l|}{ Step 1} & 0.013 & & & 0.013 & & & 0.004 \\
\hline Group $^{a}$ & $0.113^{*}$ & 2.492 & & $0.116^{*}$ & 2.537 & & 0.063 & 1.383 & \\
\hline \multicolumn{3}{|l|}{ Step 2} & 0.246 & & & 0.255 & & & 0.125 \\
\hline Positive factor & $-0.229 * * *$ & -5.659 & & $-0.125^{* *}$ & -3.110 & & $0.349 * * *$ & 8.021 & \\
\hline Negative factor & $0.464 * * *$ & 11.437 & & $0.496^{* * *}$ & 12.324 & & $-0.098^{*}$ & -2.243 & \\
\hline \multicolumn{3}{|l|}{ Step 3} & 0.248 & & & 0.260 & & & 0.136 \\
\hline Positive factor*group & -0.013 & -0.314 & & -0.068 & -1.698 & & 0.082 & 1.890 & \\
\hline Negative factor*group & 0.043 & 1.059 & & 0.044 & 1.104 & & -0.077 & -1.761 & \\
\hline \multicolumn{10}{|l|}{ Self-compassion (six facets) } \\
\hline \multicolumn{3}{|l|}{ Step 1} & 0.013 & & & 0.013 & & & 0.004 \\
\hline Group $^{a}$ & $0.113^{*}$ & 2.492 & & $0.116^{*}$ & 2.537 & & 0.063 & 1.383 & \\
\hline \multicolumn{3}{|l|}{ Step 2} & 0.274 & & & 0.269 & & & 0.168 \\
\hline Self-kindness & -0.040 & -0.709 & & -0.060 & -1.050 & & $0.124 *$ & 2.047 & \\
\hline Self-judgment & $0.113^{*}$ & 2.231 & & $0.113 *$ & 2.224 & & -0.028 & -0.513 & \\
\hline Common humanity & 0.059 & 1.125 & & 0.051 & 0.967 & & -0.085 & -1.512 & \\
\hline Isolation & $0.286^{* * *}$ & 4.771 & & $0.162 * *$ & 2.695 & & -0.120 & -1.870 & \\
\hline Mindfulness & $-0.261 * * *$ & -4.507 & & $-0.122 *$ & -2.105 & & $0.350 * * *$ & 5.645 & \\
\hline Over-identification & 0.105 & 1.785 & & $0.282 * * *$ & 4.749 & & 0.079 & 1.244 & \\
\hline \multicolumn{3}{|l|}{ Step 3} & 0.279 & & & 0.281 & & & 0.178 \\
\hline Self-kindness*group & 0.014 & 0.248 & & 0.001 & 0.011 & & 0.054 & 0.863 & \\
\hline Self-judgment*group & 0.063 & 1.218 & & 0.044 & 0.853 & & -0.004 & -0.080 & \\
\hline Common humanity* group & 0.008 & 0.143 & & -0.080 & -1.517 & & -0.022 & -0.396 & \\
\hline Isolation* group & 0.054 & 0.900 & & 0.087 & 1.449 & & -0.070 & -1.081 & \\
\hline Mindfulness* group & -0.026 & -0.441 & & -0.007 & -0.119 & & 0.037 & 0.572 & \\
\hline Over-identification* group & -0.066 & -1.104 & & -0.070 & -1.162 & & -0.006 & -0.087 & \\
\hline
\end{tabular}

factor. This suggests that these two factors of self-compassion play a different role in psychological functioning. Most research so far has focused on the total level of self-compassion, hereby overlooking the differences between the positive and the negative self-compassion factors. Our results add to the recent body of knowledge that the negative self-compassion factor is in general more strongly related to negative indicators of psychological functioning and the positive factor of selfcompassion to positive indicators (López et al. 2015; Muris and Petrocchi 2017). Regarding the six facets of self-compassion, depressive symptoms were significantly associated with higher levels of Isolation and reduced levels of Mindfulness which is in line with research among the general population (Körner et al. 2015), whereas for chronically ill patients, only the latter may foster adaptive responses to adverse events (Sirois and Rowse 2016).

\section{Limitations and Future Research}

Several limitations need to be taken into account when interpreting our findings. First, we assumed that cancer patients experience more stress than healthy controls, but we did not include a direct measure of stress. Therefore, the data does not allow to test directly the interaction between stress and mindfulness/self-compassion. It should be noted, however, that, as assumed and in line with previous research, we found that cancer patients reported more depressive symptoms and more negative affect than controls (Mozaffarieh et al. 2007; PintoGouveia et al. 2014; Schellekens et al. 2017). Second, the cross-sectional design hampers drawing conclusions about the causal direction among the study variables (i.e., mindfulness, self-compassion, and psychological functioning). We assumed that higher levels of mindfulness and self-compassion result in 
reduced depressive symptoms and negative affect and higher levels of positive affect, but it is plausible that depressed individuals become more judgmental and more critical toward themselves. However, previous studies investigating the temporal order of these constructs found that mindfulness as well as self-compassion reduced depressive symptoms, but not the other way around (Krieger et al. 2016; Snippe et al. 2015). Third, as our sample included mainly male urological cancer patients and no women with breast cancer, results may not be representative and cannot be generalized to other types of cancer patients. A final remark is that as a consequence of the many tests we conducted, the chances of multiple testing problem have substantially increased (i.e., incorrectly rejecting the null hypothesis). For this reason, caution is warranted when interpreting our results. In total, we conducted 15 tests for testing our hypotheses (i.e., 6 for mindfulness and 9 for self-compassion). Most associations that we found had significance levels of $<0.001$, so when adjusting for multiple testing (i.e., $\alpha=0.05 / 15=0.0033$ ), the majority of effects that we found would still remain significant.

Future research is needed to further examine the differential associations of distinct facets of mindfulness and selfcompassion with a range of positive and negative indicators of psychological functioning in different populations (including somatically and mentally healthy persons, somatically ill persons, persons with psychopathological symptoms) and which facets are most likely to be cultivated by interventions and are likely to be beneficial for health outcomes in these different populations.

Author Contributions LJD designed and executed the study and data analysis, and wrote the paper. JF collaborated with the design, execution, data analysis, and writing of the study. KAT collaborated with the design and in writing the study. AVR collaborated with the design and in writing the study. JGS collaborated with data collection and in writing the study. VEMM collaborated with data collection and in writing the study. RS collaborated with the design and in writing the study. MJS collaborated with the design, execution, data analysis, and writing and editing of the final manuscript. All authors approved the final version of the manuscript for submission.

Funding information This study was funded by the University Medical Center of Groningen.

\section{Compliance with Ethical Standards}

Conflict of Interest The authors declare that they have no conflicts of interest.

Ethical Approval The institutional review board of the University Medical Center of Groningen (UMCG), the Netherlands, approved the study. All procedures performed in studies involving human participants were in accordance with the ethical standards of the institutional and/or national research committee and with the 1964 Helsinki declaration and its later amendments or comparable ethical standards.

Statement of Informed Consent Informed consent was obtained from all participants.
Open Access This article is licensed under a Creative Commons Attribution 4.0 International License, which permits use, sharing, adaptation, distribution and reproduction in any medium or format, as long as you give appropriate credit to the original author(s) and the source, provide a link to the Creative Commons licence, and indicate if changes were made. The images or other third party material in this article are included in the article's Creative Commons licence, unless indicated otherwise in a credit line to the material. If material is not included in the article's Creative Commons licence and your intended use is not permitted by statutory regulation or exceeds the permitted use, you will need to obtain permission directly from the copyright holder. To view a copy of this licence, visit http://creativecommons.org/licenses/by/4.0/.

\section{References}

Baer, R. A., Smith, G. T., Hopkins, J., Krietemeyer, J., \& Toney, L. (2006). Using self-report assessment methods to explore facets of mindfulness. Assessment, 13(1), 27-45. https://doi.org/10.1177/ 1073191105283504.

Baer, R. A., Smith, G. T., Lykins, E., Button, D., Krietemeyer, J., Sauer, S., ... Williams, J. M. G. (2008). Construct validity of the five facet mindfulness questionnaire in meditating and nonmeditating samples. Assessment, 15(3), 329-342. https://doi.org/10.1177/ 1073191107313003.

Baer, R. A., Lykins, E. L. B., \& Peters, J. R. (2012). Mindfulness and selfcompassion as predictors of psychological wellbeing in long-term meditators and matched nonmeditators. The Journal of Positive Psychology, 7(3), 230-238.

Barnhofer, T., Duggan, D. S., \& Griffith, J. W. (2011). Dispositional mindfulness moderates the relation between neuroticism and depressive symptoms. Personality and Individual Differences, 51(8), 958 962. https://doi.org/10.1016/j.paid.2011.07.032.

Bergin, A. J., \& Pakenham, K. I. (2016). The stress-buffering role of mindfulness in the relationship between perceived stress and psychological adjustment. Mindfulness, 7(4), 928-939. https://doi.org/ 10.1007/s12671-016-0532-x.

Bishop, S. R., Lau, M., Shapiro, S., Carlson, L., Anderson, N. D., Carmody, J., et al. (2004). Mindfulness: A proposed operational definition. Clinical Psychology: Science and Practice, 11(3), 230 241. https://doi.org/10.1093/clipsy/bph077.

Bisschop, M. I., Kriegsman, D. M. W., Beekman, A. T. F., \& Deeg, D. J. H. (2004). Chronic diseases and depression: The modifying role of psychosocial resources. Social Science and Medicine, 59(4), 721733. https://doi.org/10.1016/j.socscimed.2003.11.038.

Bouma, J., Ranchor, A. V, Sanderman, R., \& Van Sonderen, E. (1995). Assessment of depressive symptoms with the CES-D. Manual (in Dutch).

Bränström, R., Kvillemo, P., Brandberg, Y., \& Moskowitz, J. T. (2010). Self-report mindfulness as a mediator of psychological well-being in a stress reduction intervention for cancer patients - a randomized study. Annals of Behavioral Medicine, 39(2), 151-161. https://doi. org/10.1007/s12160-010-9168-6.

Bränström, R., Duncan, L. G., \& Moskowitz, J. T. (2011). The association between dispositional mindfulness, psychological well-being, and perceived health in a Swedish population-based sample. British Journal of Health Psychology, 16(2), 300-316. https://doi.org/10. 1348/135910710X501683.

Brown, K. W., \& Ryan, R. M. (2003). The benefits of being present: Mindfulness and its role in psychological well-being. Journal of Personality and Social Psychology, 84(4), 822-848. https://doi. org/10.1037/0022-3514.84.4.822.

Brown, K. W., Weinstein, N., \& Creswell, J. D. (2012). Trait mindfulness modulates neuroendocrine and affective responses to social 
evaluative threat. Psychoneuroendocrinology, 37(12), 2037-2041. https://doi.org/10.1016/j.psyneuen.2012.04.003.

Campo, R. A., Bluth, K., Santacroce, S. J., Knapik, S., Tan, J., Gold, S., et al. (2017). A mindful self-compassion videoconference intervention for nationally recruited posttreatment young adult cancer survivors: Feasibility, acceptability, and psychosocial outcomes. Supportive Care in Cancer, 25(6), 1759-1768. https://doi.org/10. 1007/s00520-017-3586-y.

Cash, M., \& Whittingham, K. (2010). What facets of mindfulness contribute to psychological well-being and depressive, anxious, and stress-related symptomatology? Mindfulness, 1, 177-182. https:// doi.org/10.1007/s12671-010-0023-4.

Chambers, S. K., Foley, E., Clutton, S., McDowall, R., Occhipinti, S., Berry, M., et al. (2016). The role of mindfulness in distress and quality of life for men with advanced prostate cancer. Quality of Life Research, 25(12), 3027-3035. https://doi.org/10.1007/s11136016-1341-3.

Christopher, M. S., Neuser, N. J., Michael, P. G., \& Baitmangalkar, A. (2012). Exploring the psychometric properties of the five facet mindfulness questionnaire. Mindfulness, 3(2), 124-131. https://doi. org/10.1007/s12671-011-0086-x.

Ciesla, J. A., Reilly, L. C., Dickson, K. S., Emanuel, A. S., \& Updegraff, J. A. (2012). Dispositional mindfulness moderates the effects of stress among adolescents: Rumination as a mediator. Journal of Clinical Child and Adolescent Psychology, 41(6), 760-770. https:// doi.org/10.1080/15374416.2012.698724.

Coroiu, A., Kwakkenbos, L., Moran, C., Thombs, B., Cornelia, A., Bourkas, S., ... Körner, A. (2018). Structural validation of the self-compassion scale with a German general population sample. PLoS One, 13(2). https://doi.org/10.1371/journal.pone.0190771.

Costa, J., Marôco, J., Pinto-Gouveia, J., Ferreira, C., \& Castilho, P. (2016). Validation of the psychometric properties of the selfcompassion scale. Testing the factorial validity and factorial invariance of the measure among borderline personality disorder, anxiety disorder, Eating Disorder and General Populations. Clinical Psychology \& Psychotherapy, 23(5), 460-468. https://doi.org/10. 1002/cpp.1974.

de Bruin, E. I., Topper, M., Muskens, J. G. A. M., Bogels, S. M., \& Kamphuis, J. H. (2012). Psychometric properties of the five facets mindfulness questionnaire (FFMQ) in a meditating and a nonmeditating sample. Assessment, 19(2), 187-197. https://doi.org/10. 1177/1073191112446654

Garland, S. N., Campbell, T., Samuels, C., \& Carlson, L. E. (2013a). Dispositional mindfulness, insomnia, sleep quality and dysfunctional sleep beliefs in post-treatment cancer patients. Personality and Individual Differences, 55(3), 306-311. https://doi.org/10.1016/j. paid.2013.03.003.

Garland, S. N., Tamagawa, R., Todd, S. C., Speca, M., \& Carlson, L. E. (2013b). Increased mindfulness is related to improved stress and mood following participation in a mindfulness-based stress reduction program in individuals with Cancer. Integrative Cancer Therapies, 12(1), 31-40. https://doi.org/10.1177/ 1534735412442370 .

Harrell, F. E. (2001). Regression modeling strategies, with applications to linear models, survival analysis and logistic regression. New York: Springer.

Keng, S. L., Smoski, M. J., \& Robins, C. J. (2011). Effects of mindfulness on psychological health: A review of empirical studies. Clinical Psychology Review, 31(6), 1041-1056. https://doi.org/10.1016/j. cpr.2011.04.006.

Körner, A., Coroiu, A., Copeland, L., Gomez-Garibello, C., Albani, C., Zenger, M., \& Brähler, E. (2015). The role of self-compassion in buffering symptoms of depression in the general population. PLoS One, 10(10), 1-14. https://doi.org/10.1371/journal.pone.0136598.

Krieger, T., Berger, T., \& Holtforth, M. G. (2016). The relationship of self-compassion and depression: cross-lagged panel analyses in depressed patients after outpatient therapy. Journal of Affective Disorders, 202, 39-45. https://doi.org/10.1016/j.jad.2016.05.032.

Kumlander, S., Lahtinen, O., Turunen, T., \& Salmivalli, C. (2018). Two is more valid than one, but is six even better? The factor structure of the self-compassion scale (SCS). PLoS One, 13(12), 1-22. https:// doi.org/10.1371/journal.pone.0207706.

Lazarus, R. S., \& Folkman, S. (1984). Stress, appraisal, and coping. New York: Springer Publishing Company.

López, A., Sanderman, R., Smink, A., Zhang, Y., Eric, V. S., Ranchor, A., \& Schroevers, M. J. (2015). A reconsideration of the selfcompassion scale's total score: Self-compassion versus self-criticism. PLoS One, 10(7), 1-12. https://doi.org/10.1371/journal.pone. 0132940.

López, A., Sanderman, R., \& Schroevers, M. J. (2016). Mindfulness and self-compassion as unique and common predictors of affect in the general population. Mindfulness, 7(6), 1289-1296. https://doi.org/ 10.1007/s12671-016-0568-y.

Macbeth, A., \& Gumley, A. (2012). Clinical psychology review exploring compassion: a meta-analysis of the association between selfcompassion and psychopathology. Clinical Psychology Review, 32(6), 545-552. https://doi.org/10.1016/j.cpr.2012.06.003.

Marks, A. D. G., Sobanski, D. J., \& Hine, D. W. (2010). Do dispositional rumination and/or mindfulness moderate the relationship between life hassles and psychological dysfunction in adolescents? The Australian and New Zealand Journal of Psychiatry, 44(9), 831838. https://doi.org/10.3109/00048674.2010.487478.

Moos, R., \& Schaefer, J. (1993). Coping resources and processes: Current concepts and measures. In L. Goldberger \& S. Brexnitz (Eds.), Handbook of stress: Theoretical and clinical aspects. New York: Free Press.

Mozaffarieh, M., Sacu, S., Benesch, T., \& Wedrich, A. (2007). Mental health measures of anxiety and depression in patients with retinal detachment. Clinical Practice and Epidemiology in Mental Health CP EMH, 3, 10. https://doi.org/10.1186/1745-0179-3-Received.

Muris, P., \& Petrocchi, N. (2017). Protection or vulnerability ? A metaanalysis of the relations between the positive and negative components of self-compassion and psychopathology literature search and selection of studies. Clinical Psychology \& Psychotherapy, 24(2), 373-383. https://doi.org/10.1002/cpp.2005.

Muris, P., Otgaar, H., \& Pfattheicher, S. (2018). Stripping the forest from the rotten trees: compassionate self-responding is a way of coping, but reduced uncompassionate self-responding mainly reflects psychopathology. Mindfulness, 10(2), 196-199.

Neff, K. D. (2003). The development and validation of a scale to measure self-compassion. Self and Identity, 2(3), 223-250. https://doi.org/10. 1080/15298860390209035.

Neff, K. D. (2016). The self-compassion scale is a valid and theoretically coherent measure of self-compassion. Mindfulness, 7(1), 264-274. https://doi.org/10.1007/s12671-015-0479-3.

Neff, K. D., \& Vonk, R. (2009). Self-compassion versus global self-esteem: Two different ways of relating to oneself. Journal of Personality, 77(1), 23-50. https://doi.org/10.1111/j.1467-6494. 2008.00537.x.

Neff, K. D., Whittaker, T. A., \& Karl, A. (2017). Examining the factor structure of the self-compassion scale in four distinct populations: Is the use of a Total scale score justified? Journal of Personality Assessment, 99(6), 596-607. https://doi.org/10.1080/00223891. 2016.1269334

Neff, K. D., Long, P., Knox, M. C., Davidson, O., Kuchar, A., Costigan, A., \& Williamson, Z. (2018a). The forest and the trees: Examining the association of self-compassion and its positive and negative components with psychological functioning. Self and Identity, 17(6), 627-645. https://doi.org/10.1080/15298868.2018.1436587.

Neff, K. D., Tóth-Király, I., Yarnell, L. M., Arimitsu, K., Castilho, P., Ghorbani, N., et al. (2018b). Examining the factor structure of the self-compassion scale in 20 diverse samples: support for use of a 
Total score and six subscale scores. Psychological Assessment, 31(1), 27-45. https://doi.org/10.1037/pas0000629.

Nyklíček, I., \& Kuijpers, K. F. (2008). Effects of mindfulness-based stress reduction intervention on psychological well-being and quality of life: Is increased mindfulness indeed the mechanism? Annals of Behavioral Medicine, 35(3), 331-340. https://doi.org/10.1007/ s12160-008-9030-2.

Peeters, F., Ponds, R., Boon-Vermeeren, M. T. G., Hoorweg, M., Kraan, H., \& Meertens, L. (1999). Handleiding bij de Nederlandse vertaling van de Positive and Negative Affect Schedule (PANAS). Maastricht: Universiteit Maastricht, Vakgroep Psychiatrie En Neuropsychologie.

Penninx, B. W. J. H., Van Tilburg, T., Joan, A. J. P., Deeg, D. J. H., Kriegsman, D. M. W., \& Van Eijk, J. T. M. (1998). Effects of social support and personal coping resources on depressive symptoms: Different for various chronic diseases? Health Psychology, 17(6), 551-558. https://doi.org/10.1037/0278-6133.17.6.551.

Petrocchi, N., Ottaviani, C., \& Couyoumdjian, A. (2014). Dimensionality of self-compassion : Translation and construct validation of the selfcompassion scale in an Italian sample. Journal of Mental Health, 23(2), 72-77. https://doi.org/10.3109/09638237.2013.841869.

Pinto-Gouveia, J., Duarte, C., Matos, M., \& Fráguas, S. (2014). The protective role of self-compassion in relation to psychopathology symptoms and quality of life in chronic and in cancer patients. Clinical Psychology \& Psychotherapy, 21(4), 311-323. https://doi. org/10.1002/cpp.1838.

Radloff, L. (1977). The CES-D scale: A self-report depression scale for research in the general population. Applied Psychological Measurement, 1(3), 385-401. https://doi.org/10.1177/ 014662167700100306

Schellekens, M. P. J., Karremans, J. C., Drift, M. A., Molema, J., Hurk, D. G. M., Prins, J. B., \& Speckens, A. E. M. (2017). Are mindfulness and self-compassion related to psychological distress and communication in couples facing lung Cancer ? A dyadic approach. Mindfulness, 8(2), 325-336. https://doi.org/10.1007/s12671-0160602-0.
Schroevers, M. J., Ranchor, A. V., \& Sanderman, R. (2003). The role of social support and self-esteem in the presence and course of depressive symptoms: A comparison of cancer patients and individuals from the general population. Social Science and Medicine, 57(2), 375-385. https://doi.org/10.1016/S0277-9536(02)00366-0.

Sirois, F. M., \& Rowse, G. (2016). The role of self-compassion in chronic illness care. Journal of Clinical Outcomes Management, 23(11), 521-527.

Snippe, E., Nyklicek, I., Schroevers, M. J., \& Bos, E. H. (2015). The temporal order of change in daily mindfulness and affect during mindfulness-based stress reduction. Journal of Counseling Psychology, 62(2), 106-114. https://doi.org/10.1037/cou0000057.

Takahashi, T., Sugiyama, F., Kikai, T., Kawashima, I., Guan, S., Oguchi, M., ... Kumano, H. (2019). Changes in depression and anxiety through mindfulness group therapy in Japan: The role of mindfulness and self-compassion as possible mediators. BioPsychoSocial Medicine, 13(1), 1-10. https://doi.org/10.1186/s13030-019-0145-4.

Watson, D., Clark, L. A., \& Tellegen, A. (1988). Development and validation of brief measures of positive and negative affect: The PANAS scales. Journal of Personality and Social Psychology, 54(6), 1063-1070. https://doi.org/10.1037/0022-3514.54.6.1063.

Witek-Janusek, L., Tell, D., \& Mathews, H. L. (2019). Mindfulness based stress reduction provides psychological benefit and restores immune function of women newly diagnosed with breast Cancer: A randomized trial with active control. Brain, Behavior, and Immunity, 80, 358-373. https://doi.org/10.1016/j.bbi.2019.04.012.

Zessin, U., Dickhäuser, O., \& Garbade, S. (2015). The relationship between self-compassion and well-being: A meta-analysis. Applied Psychology. Health and Well-Being, 7(3), 340-364. https://doi.org/ 10.1111/aphw.12051.

Publisher's Note Springer Nature remains neutral with regard to jurisdictional claims in published maps and institutional affiliations. 